Review

\title{
Crosstalk between Fibroblast Growth Factor (FGF) Receptor and Integrin through Direct Integrin Binding to FGF and Resulting Integrin-FGF-FGFR Ternary Complex Formation
}

\author{
Seiji Mori ${ }^{1}$ and Yoshikazu Takada ${ }^{2, *}$
}

1 Department of Molecular Pathology, Osaka University Graduate School of Medicine,

Division of Health Sciences, 1-7 Yamada-oka, Suita-shi, Osaka 565-0871, Japan;

E-Mail: mori@sahs.med.osaka-u.ac.jp

2 Departments of Dermatology and Molecular Medicine, School of Medicine, University of California, Davis, Sacramento, CA 95817, USA

* Author to whom correspondence should be addressed; E-Mail: ytakada@ucdavis.edu; Tel.: +1-916-734-7443; Fax: +1-916-734-7505.

Received: 13 June 2013; in revised form: 6 August 2013 / Accepted: 8 August 2013 /

Published: 13 August 2013

\begin{abstract}
Fibroblast growth factors (FGFs) play a critical role in diverse physiological processes and the pathogenesis of diseases. Integrins are involved in FGF signaling, since integrin antagonists suppress FGF signaling. This is called integrin-FGF crosstalk, while the specifics of the crosstalk are unclear. This review highlights recent findings that FGF1 directly interacts with integrin $\alpha v \beta 3$, and the resulting integrin-FGF-fibroblast growth factor receptor (FGFR) ternary complex formation is essential for FGF1-induced cell proliferation, migration and angiogenesis. An integrin-binding defective FGF1 mutant (Arg-50 to Glu, R50E) is defective in ternary complex formation and in inducing cell proliferation, migration and angiogenesis, while R50E still binds to the FGF receptor and heparin. In addition, R50E suppressed tumorigenesis in vivo, while wild-type (WT) FGF1 enhanced it. Thus, the direct interaction between FGF1 and integrin $\alpha v \beta 3$ is a potential therapeutic target, and $\mathrm{R} 50 \mathrm{E}$ is a potential therapeutic agent.
\end{abstract}

Keywords: FGF1; integrin; crosstalk; dominant-negative mutant 


\section{Introduction}

It has been proposed that biological processes of all multicellular organisms require signals from growth factor receptors and those from adhesion receptor integrins [1]. A family of FGFs and their receptors regulate numerous physiological, as well as pathological processes, including cell proliferation, survival, motility, differentiation and angiogenesis [2-4]. These biological activities induced by FGFs require integrins [5,6]. The integrin family of cell adhesion receptors mediates cell-extra cellular matrix and cell-cell interaction and also transduces signals [7]. It has been believed that integrins and growth factor receptors can independently propagate intracellular signals, but they interact with one another on multiple levels on the pathway [8]. In current models of integrin-growth factor crosstalk, integrins bind to extracellular matrix proteins, and growth factor receptors bind to growth factors. Additionally, two separate signals merge with one another in multiple levels inside the cells $[1,8,9]$. In contrast to current models, we discovered that FGF1 directly binds to integrin $\alpha v \beta 3$ and induces the FGFR1-FGF1-integrin $\alpha v \beta 3$ ternary complex [10]. In this review, we will summarize recent findings on the fibroblast growth factor receptor (FGFR)-integrin crosstalk, in which FGF directly interacts with integrin $\alpha v \beta 3$.

\section{Fibroblast Growth Factors (FGFs) are Multi-Functional Growth Factors}

FGFs control multiple biological processes, such as proliferation, survival, migration and differentiation of a variety of cell types [4,11]. The human and mouse FGF family consists of 22 related polypeptides that are expressed in almost all tissues. They can be divided into seven groups based on their evolutionary relationships: FGF1 and 2, FGF4-6, FGF3, 7, 10 and 22, FGF8, 17 and 18, FGF9, 16 and 20, FGFs-11-14 and FGF19, 21 and 23 [2]. FGF1, FGF2 and FGFs-11-14 are synthesized without signal sequence for secreting. Despite the lack of this sequence, FGF1 and FGF2 can be secreted by an unconventional manner, i.e., independent of the ER/Golgi pathway [12-16]. The FGFs-11-14, called intracellular FGFs (iFGFs) or fibroblast growth factor homologous factors (FHFs), are found as exclusively intracellularly residing FGFs and act in an FGFR-independent fashion [17]. The function of iFGFs remain unclear, but might be engaged in signaling and ion channel regulation, since iFGFs bind to a neuronal MAP kinase scaffold protein, isletbrain-2 (IB2) and to voltage-gated sodium channels (VGSCs) [18,19]. The hormone-like FGFs, -19, -21 and -23 (hFGFs), are secreted in an endocrine manner and regulate metabolism, such as lipid metabolism, glucose uptake, inorganic phosphate level, and insulin sensitivity [20-22].

Among the FGF family members, FGF1 and FGF2 are prototypic FGF and have been extensively characterized. They were originally isolated from the brain and pituitary as mitogens for cultured fibroblasts [23,24]. FGF1 has been implicated in a range of physiological processes, including development, wound healing, and cardiovascular changes [3]. Surprisingly, FGF1 knockout mice are viable and normal under standard laboratory conditions, the physiological role of FGF1 is not clear [25]. FGF2 knockout mice are also viable, but have decreased vascular smooth muscle contractility and displayed cerebral cortex defects [26,27]. 


\section{Signal Transduction of FGF and FGFR}

FGFs mediate their biological responses as extracellular proteins by binding to and activating the cell surface FGF receptors (FGFRs). The FGFRs consist of four structurally related receptor tyrosine kinases (FGFR1-4); in addition to these genes, alternative splicing variants of FGFR1-3 provide variations for ligand specificity [28,29]. FGFRs are composed of three extracellular immunoglobulin domains (D1-D3), the transmembrane domain and the cytoplasmic tyrosine kinase domain $[2,29,30]$. The FGF ligands bind the D2-D3 fragment of the FGFR, which results in the receptor dimerization and subsequent autophosphorylation of specific tyrosine residues within the intracellular domain. This leads to the activation of intracellular signaling cascades. The four main signaling pathways downstream of receptor activation are (1) the Janus kinase/signal transducer and activator of transcription (Jak/Stat), (2) phosphoinositide phospholipase C (PLC $\gamma)$, (3) phosphatidylinositol 3-kinase (PI3K) and (4) mitogen-activated protein kinase/extracellular signal-regulated kinase (MAPK/Erk) [3,4,11].

Binding specificity between FGFs and FGFRs is determined by amino acid sequence differences of both 18 FGFs and seven cardinal FGFRs (FGFR1b, 1c, 2b, 2c, 3b, 3c and 4), by spatial and temporal expression patterns of these proteins and, also, is regulated by co-factors, such as heparan sulfate glycosaminoglycan (HSGAG) and cell adhesion molecules. Intriguingly, FGF1 binds to all known cell-surface FGFR isoforms [3,31].

\section{Role of FGF and FGFR in Tumorigenesis, Tumor Angiogenesis, and Inflammation}

The underlying mechanisms of FGF signaling in tumors are classified into four types: (1) activating mutations of FGFR; (2) FGF or FGFR overexpression due to gene amplification; (3) chromosomal translocation-derived FGFR fusion proteins and (4) FGF ligand-dependent autocrine or paracrine signaling [32,33]. Through these mechanisms, deregulated FGF signaling facilitates tumor development by affecting downstream biological processes, cell proliferation, migration, invasiveness, and tumor angiogenesis [32]. The FGFR aberrations mentioned above can be observed in many cancer tissues, such as mammary gland, bladder, prostate, endometrial, lung and brain [33].

FGFs are potent mitogens for cancer cells. In fact, high expression of FGFs has been reported in several tumors. More than $80 \%$ of prostate cancer cells express FGF8, and the levels of FGF8 expression correlate with the levels of invasiveness [34]. FGF19 is also expressed in prostate cancer and acts in an autocrine fashion, although it is categorized into endocrine FGF [35]. In breast cancer cells, cells that overexpress FGF1 or FGF4 grow faster than cells with low FGF expression in vivo [36]. Amplification of FGF3 is detected over $20 \%$ of the primary breast carcinomas and shows a significant relationship to lymph node metastases [37,38]. In ovarian adenocarcinoma, the levels of amplification of FGF1 at chromosome 5q31 correlate with those of FGF1 mRNA and protein expression and the number of CD31-positive blood vessels [39]. The levels of FGFR expression also correlate with the invasiveness of cancer [40]. FGF1/FGFR-1 signaling (both autocrine and paracrine loops) thus potentially plays a critical role in cancer progression. Because FGF signaling enhances multiple biological processes that promote tumor progression, it is an attractive therapeutic target, particularly since therapies targeting FGF receptors and/or FGF signaling can affect both the tumor cells directly and tumor angiogenesis. 
It should be noted, however, that the role of FGF signaling in tumor progression is still controversial. In some tumors, FGFR expression is downregulated, suggesting that FGFRs can act as tumor suppressors. FGFR2 is downregulated or lost in thyroid tumors [41], salivary gland tumor [42] and most hepatocellular carcinoma cell lines and tissues [43]. FGFR4 is also downregulated in fibroblasts in pulmonary adenocarcinoma [44]. These FGFRs might play a role in the maintenance of homeostasis rather than tumorigenicity; however, it remains unknown how FGFRs negatively affects tumorigenesis and the invasiveness of tumor cells.

FGF plays a role in pathological angiogenesis in inflammatory diseases, as well. Transient exposure to FGF1 upregulates the expression of the cell adhesion molecules, ICAM (intercellular adhesion molecule)-1 and VCAM (vascular cell adhesion molecule)-1, in endothelial cells and increases polymorphonuclear leukocyte adhesion and transendothelial migration [45].

\section{Integrin-Growth Factor Receptor Crosstalk}

Integrins are a family of cell adhesion receptors that recognize extracellular matrix ligands and cell surface ligands [46]. Integrins are transmembrane $\alpha-\beta$ heterodimers, and at least $18 \alpha$ and $8 \beta$ subunits are known [7]. Integrins serve as transmembrane mechanical links between the extracellular contacts and the cytoskeleton by the actin-based microfilament system. Multiple submembrane linker proteins connect the cytoplasmic domains of integrins to the cytoskeleton, resulting in complex interactions [46]. In addition to the function in cell adhesion, integrins are involved in signal transduction upon ligand binding, and their functions are, in turn, regulated by signals from within the cell [7]. Ligation of integrins triggers a large variety of signal transduction events that contribute to modulate cell proliferation, survival/apoptosis, shape, polarity, motility, gene expression and differentiation.

These integrin-mediated events can also be initiated by growth factor receptors, implying that integrins and growth factor receptors coordinately support cell behavior. For example, integrin-mediated cell adhesion to the ECM proteins is influenced by stimulation of cells with epidermal growth factors (EGF), platelet-derived growth factors (PDGF), insulin-like growth factor-1 (IGF1) or vascular endothelial growth factor (VEGF) [47-50]. EGF- or IGF1-induced vascular smooth muscle cell migration, proliferation and survival depend on integrin $\alpha v \beta 3$ [51,52]. Moreover, FGF2-, VEGF- or TNF- $\alpha$-induced endothelial cell adhesion, migration and angiogenesis depend on integrin $\alpha v \beta 3, \alpha 5 \beta 1$ and $\alpha v \beta 5$ [53-56]. In contrast to the crosstalk that involves growth factors, Zou et al. demonstrate that fibronectin activates FGFR1 through a pathway that requires integrin $\beta 1$, but not FGF [57].

Integrins and growth factor receptors interact with each other at several levels in the pathway: (1) integrins control growth factor receptor activity by recruiting of adaptor proteins proximal to growth factor receptors; (2) integrins modulate growth factor receptor activity by changing their localization to focal contacts, where signaling molecules are accumulated; (3) growth factor receptors control integrin-dependent cell adhesion and motility by regulating binding affinity to ligands; (4) growth factor receptor regulates the integrin-associated signaling proteins, such as FAK, Src and PI3K, and regulates the downstream regulatory proteins, such as ERK, Akt, JNK and the Rho GTPases [8,9]. These collaborative signaling events include direct or indirect physical interaction between integrins and growth factor receptors $[47,48,58,59]$. 
Several growth factors have been reported to act as direct ligands for integrins (Table 1). For instance, FGF1 directly binds integrin $\alpha \mathrm{v} \beta 3$, and the interaction is required for fibroblast proliferation and migration [10]. IGF1 directly binds to integrin $\alpha v \beta 3$ and $\alpha 6 \beta 4$ [60] and serves to regulate IGF signaling in anchorage-independent conditions [61]. Furthermore, neuregulin-1, an EGF family member, binds to integrin $\alpha v \beta 3$ and $\alpha 6 \beta 4$ and, thereby, induces integrin-neuregulin-1-ErbB3 (a member of the EGF receptor family, a specific neuregulin-1 receptor) complex [62]. Vascular endothelial growth factor-C (VEGF-C) and VEGF-D binds $\alpha 9 \beta 1$ and induced $\alpha 9 \beta 1$-dependent Erk and paxillin phosphorylation [63]. Additionally, VEGF-A binds integrin $\alpha 3 \beta 1$ and $\alpha 9 \beta 1$ and contributes to angiogenesis $[64,65]$. Activation of TGF- $\beta$ depends on the binding of latent TGF- $\beta$ to integrin $\alpha v \beta 6$ or integrin $\alpha v \beta 8$ [66,67]. Other examples include nerve growth factor (NGF), neurotropin-3 (NT3) and fractalkine, a transmembrane chemokine (Table 1).

Table 1. Direct interactions between growth factors and integrins.

\begin{tabular}{ccc}
\hline Growth factor & Integrins & References \\
\hline Angiopoietin-1 & $\alpha 5 \beta 1$ & {$[68]$} \\
Angiopoietin-2 & $\alpha 5 \beta 1, \beta 2$ & {$[68,69]$} \\
CD40 ligand & $\alpha \operatorname{IIb} \beta 3, \alpha 5 \beta 1, \alpha \mathrm{M} \beta 2$ & {$[70-72]$} \\
FGF-1 & $\alpha v \beta 3$ & {$[10]$} \\
FGF-2 & $\alpha v \beta 3$ & {$[73]$} \\
Fractalkine & $\alpha v \beta 3, \alpha 4 \beta 1$ & {$[74]$} \\
Pro HB-EGF & $\alpha 3 \beta 1$ & {$[75]$} \\
IGF-1 & $\alpha v \beta 3, \alpha 6 \beta 4$ & {$[60,61]$} \\
LTGF- $\beta$ & $\alpha 6 \beta 4, \alpha v \beta 8$ & {$[66,67]$} \\
Neuregulin-1 & $\alpha v \beta 3, \alpha 6 \beta 4$ & {$[62]$} \\
NGF & $\alpha 9 \beta 1$ & {$[76]$} \\
NT3 & $\alpha 9 \beta 1$ & {$[76]$} \\
Semaphorin 7A & $\alpha 1 \beta 1$ & {$[77]$} \\
VEGF-A & $\alpha 3 \beta 1$ & {$[64]$} \\
VEGF-C & $\alpha 9 \beta 1$ & {$[63]$} \\
VEGF-D & $\alpha 9 \beta 1$ & {$[63]$} \\
\hline
\end{tabular}

Ligand-binding function of integrins plays a role in integrin-FGF receptor crosstalk. Blocking antibodies for integrin $\alpha v \beta 3$ diminishes FGF2-induced vascular growth and endothelial cell migration, suggesting that the FGF signaling cooperates with integrin $\alpha v \beta 3$ in angiogenesis $[53,55]$. How do FGFs and integrins crosstalk? It has been reported that immobilized FGF2 facilitates endothelial cell adhesion through direct interaction with integrin $\alpha v \beta 3$ [73] and induces endothelial cell proliferation, motility and recruitment of FGFR1 at the cell-substratum contact [78]. However, because heat-denatured FGF2 still supports integrin binding [78], it is unclear whether this interaction is biologically relevant or how integrins interact with FGF2. It has also been reported that FGF2 binds to fibrinogen, which induces endothelial cell proliferation and subsequent co-localization of $\alpha v \beta 3$ and FGFR1 [79,80]. However, because FGF1 does not bind to fibrinogen [81], fibrinogen mediated FGF-integrin crosstalk cannot be applied to FGF1 and, also, perhaps, not to other members of the FGF family. Thus, there may be an alternative model by which FGF1 crosstalks with the integrins. 


\section{Crosstalk between Integrin $\alpha v \beta 3$ and FGFR through Direct Binding to FGF}

Computational simulation of FGF1 and integrin $\alpha v \beta 3$ interaction predicts direct interaction of FGF1 and $\alpha v \beta 3$ (Figure 1a). FGF1 directly binds to soluble and cell-surface integrin $\alpha v \beta 3$ (Kd about $1 \mu \mathrm{M})$. Antagonists to $\alpha \mathrm{v} \beta 3$ (mAb 7E3 and cyclic RGDfV) block this interaction [10]. The CYDMKTTC sequence (the specificity loop) within the ligand-binding site of $\beta 3$ plays a role in FGF1 binding (Figure 1b), suggesting that FGF1 binds to a binding site common to other av $\beta 3$ ligands (classical RGD-binding site) [10]. The integrin binding site in FGF1 is distinct from the FGFR-binding site (Figure 1c). The structure of the FGF1-FGFR complex (Protein data base (PDB) code 1E0O) was superimposed on the FGF1-integrin $\alpha v \beta 3$ complex model, resulting in the putative integrin-FGFFGFR ternary complex structure (Figure 2a). Thus, this model predicts that the integrin-FGF-FGFR ternary complex can be generated with little or no steric hindrance. In fact, wild-type (WT) FGF1 induces ternary complex formation, which is detected by co-precipitation of FGFR and integrin $\alpha v \beta 3$ [82]. We propose a model in which integrin and FGFR bind to FGF1 simultaneously and make a ternary complex on the cell surface upon FGF1 stimulation (Figure 2b).

We generated a point mutant (Arg at position 50 in FGF1 to Glu, R50E) within the predicted integrin-binding interface based on the docking model. R50E is defective in integrin binding, but normal in heparin and FGFR binding [10]. Interestingly, R50E is defective in DNA synthesis, cell proliferation, cell migration and chemotaxis, suggesting that the direct integrin binding to FGF1 is critical for FGF signaling, while it binds to FGFR1 and heparin [10]. Interestingly, R50E is defective in ternary complex formation, as predicted from the model [82], suggesting that the process is critical for FGF signaling.

It has been reported that the extracellular domain of integrin $\alpha v \beta 3$ can form both bent and extended conformations based on electron microscopy and the crystal structures of integrins [83,84]. It has been proposed that a high affinity state is related to an extended conformation with an open headpiece [85]. It has also been reported that most of the ligand (fibronectin) bound integrin complexes are in a bent conformation [86]. In extended integrins, the ligand-binding site reaches up to approximately $200 \AA$ from the plasma membrane [83]. It is unclear if integrin $\alpha v \beta 3$ in the ternary complex has an extended conformation, since the FGF binding site in FGFR is estimated to be located about $50 \AA$ from the membrane.

ERK1/2 activation can be divided into a transient phase (within three hours of stimulation) and a sustained phase (after three hours) in NIH3T3 cells [87]. Sustained ERK1/2 activation is integrin-dependent and crucial to cell cycle entry upon FGF stimulation [55,87]. The time-course of ERK1/2 activation shows that WT FGF1 induces both transient and sustained activation of ERK1/2 in NIH3T3 cells [82]. In contrast, R50E is defective in inducing sustained ERK1/2 activation, while it induces transient ERK1/2 activation. R50E induces transient activation, but is defective in sustained activation of FGFR1 and FRS2 $\alpha$, as well [82]. It is, thus, likely that the inability of R50E to induce sustained ERK1/2 activation is related to its defect in inducing cell cycle entry. It is interesting to study how the ternary complex formation is related to sustained ERK1/2 activation. 
Figure 1. Docking simulation of fibroblast growth factor 1 (FGF1)-integrin $\alpha v \beta 3$ and identification of the integrin-binding site in FGF1. (a) Model of FGF1-integrin interaction. Docking simulation of the interaction between FGF1 (PDB code 1AXM) and integrin $\alpha v \beta 3$ (PDB code 1L5G) was performed as described in [10]. 1AXM was used for the docking, and 1L5G (headpiece of integrin $\alpha v \beta 3$ ) was used as a receptor. This pose indicates the most stable state of FGF1 when FGF1 interacts with integrin $\alpha v \beta 3$. (b) Mutagenesis analysis reveals that indicated basic amino acids within the integrin-binding interface in FGF1 are responsible for the interaction between FGF1 and integrin $\alpha v \beta 3$. The specificity loop in the I-like domain of $\beta 3$ plays a critical role in binding FGF1 to integrin $\alpha v \beta 3$. (c) It is noteworthy that the positions of the amino acid residues (E102, Y109, and N110) at the fibroblast growth factor receptor (FGFR)-binding site are distinct from the predicted integrin-binding site.

a.

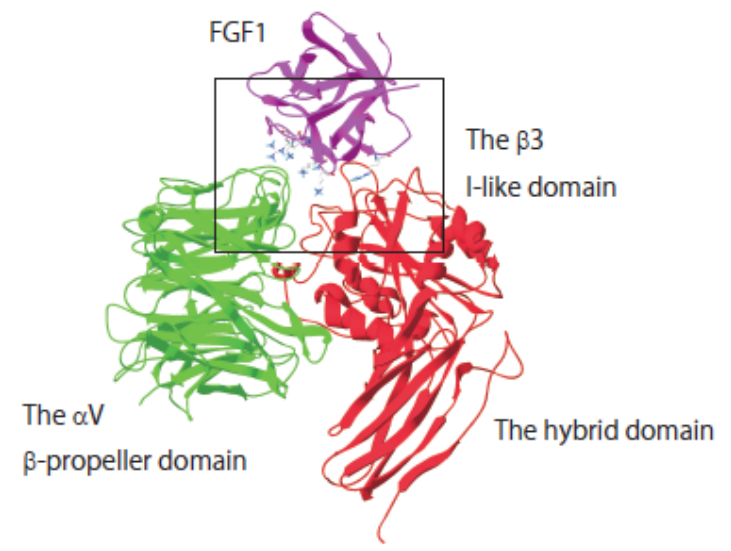

b.

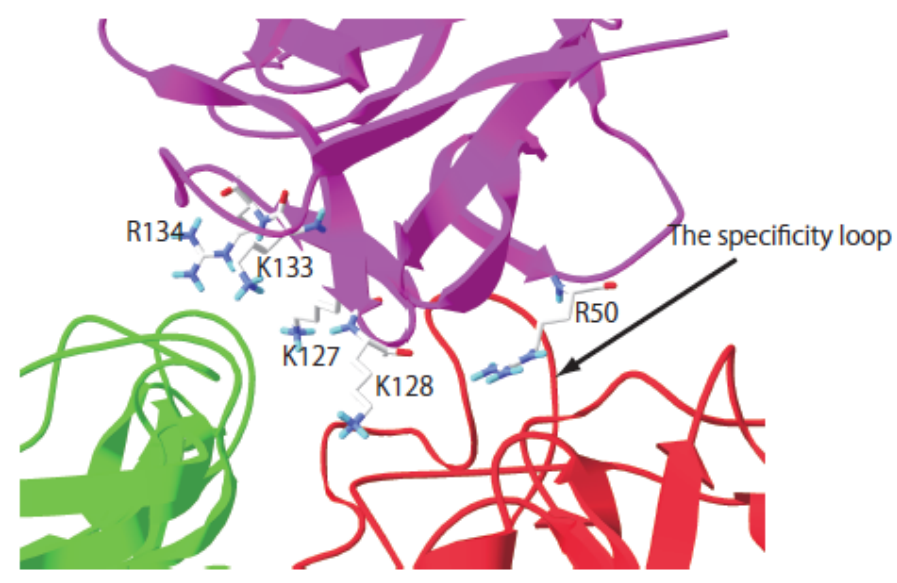

c.

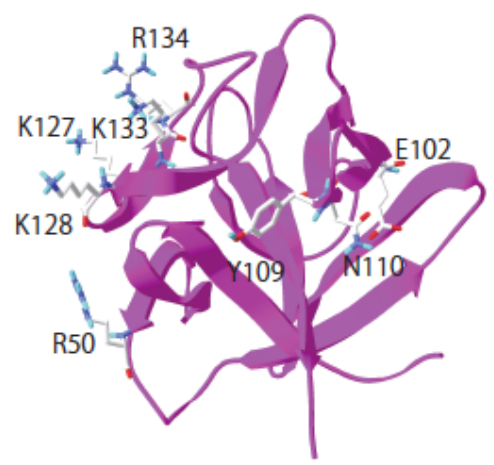


Figure 2. A model of an FGF-FGFR-integrin ternary complex. (a) FGF1-FGFR2 crystal structure (PDB code 1E0O) was superimposed on the simulated FGF1-integrin av $\beta 3$ complex; (b) a schematic model of the FGF1-FGFR-integrin ternary complex was depicted based on (a). FGF1 and FGFR complexes juxtapose in a symmetric dimer (two-end model). Two receptors contact each other through D2 domains [88]. Integrins interact with FGFs that are located outside the FGFR dimer (integrin is shown on only one-side). According to the predicted structure of (a) and the differences in the molecular size between FGFR and integrin $\alpha v \beta 3$, integrin $\alpha v \beta 3$ may form a bent conformation to bind FGF1. The common signaling pathways of FGFR and integrin are the Ras/Raf/Mek pathway (red), the PI3K/AKT pathway (purple) and the PLCr pathway (blue). Complex formation is required for mediating signals to elicit cell proliferation, migration and angiogenesis [82]. D1-D3, Ig-like domains, 1 to 3; AB, acid box; TM, transmembrane domain; TK, tyrosine kinase domain; KI, kinase insert; $\alpha$, integrin $\alpha \mathrm{v} ; \beta$, integrin $\beta 3$.

a

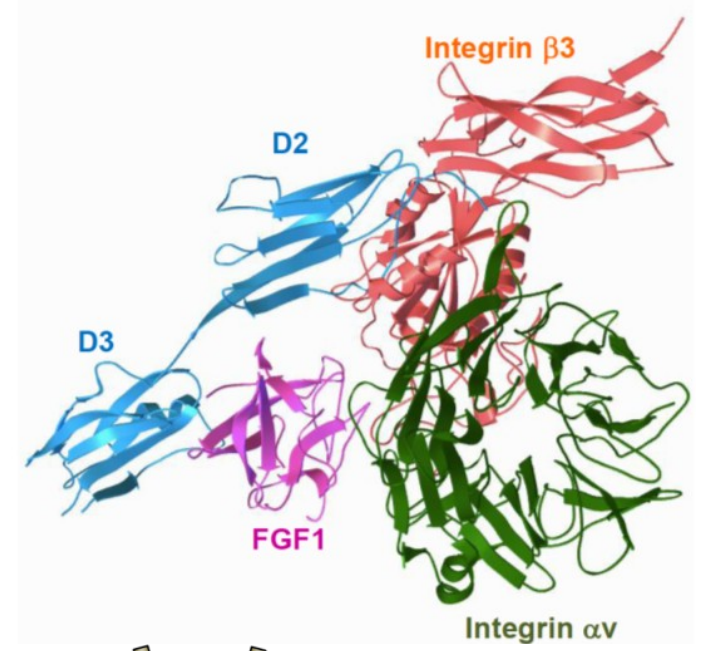

$\mathrm{b}$

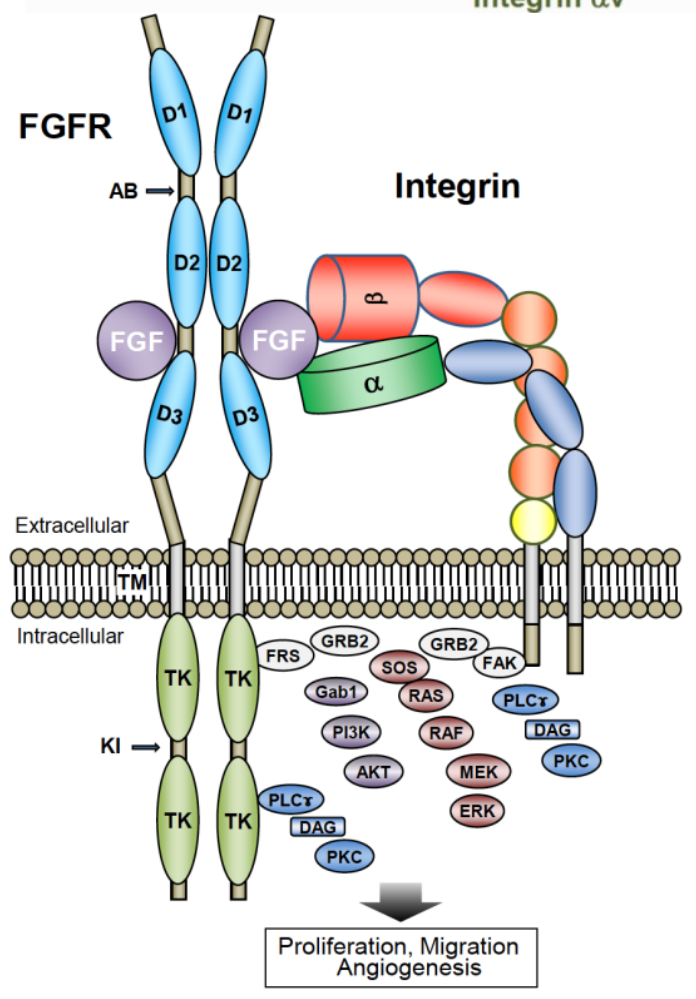




\section{R50E Is a Dominant-Negative Antagonist of FGFR}

If ternary complex formation (integrin-FGF-FGFR) is required to induce signals, it is predicted that the R50E mutant should compete with WT FGF1 for binding to integrins. Thus, R50E should be antagonistic. We found that this is the case. Excess R50E suppresses DNA synthesis, cell viability, and angiogenesis induced by WT FGF1 [82]. We thus conclude that: (1) ternary complex formation is required for FGF signaling; (2) the defect of R50E to bind to integrin and subsequent ternary complex formation is directly related to the functional defect in R50E; and (3) R50E is a dominant-negative mutant (Figure 3). These results suggest that R50E has therapeutic potential [82]. Using cancer cells that stably express WT FGF1 or R50E, WT FGF1 markedly enhanced tumorigenesis, and R50E suppressed it [89]. Furthermore, R50E suppressed angiogenesis in different assays (tube formation assays, Matrigel plug assays, rat aorta ring assays and chick embryo chorioallantoic membrane (CAM) assays [89]). These results suggest that R50E has translational potential as an anti-angiogenesis and anti-cancer therapeutic agent.

Figure 3. The integrin-binding defective mutant (R50E) is incapable of inducing signals. Ternary complex formation (integrins-FGF-FGFR) is required for signaling. R50E competes with wild-type (WT) FGF1 for binding to integrins. Thereby, dominant-negative effects were observed when treated cells with an excess of R50E in WT FGF1 induced cell proliferation, migration and, also, angiogenesis.

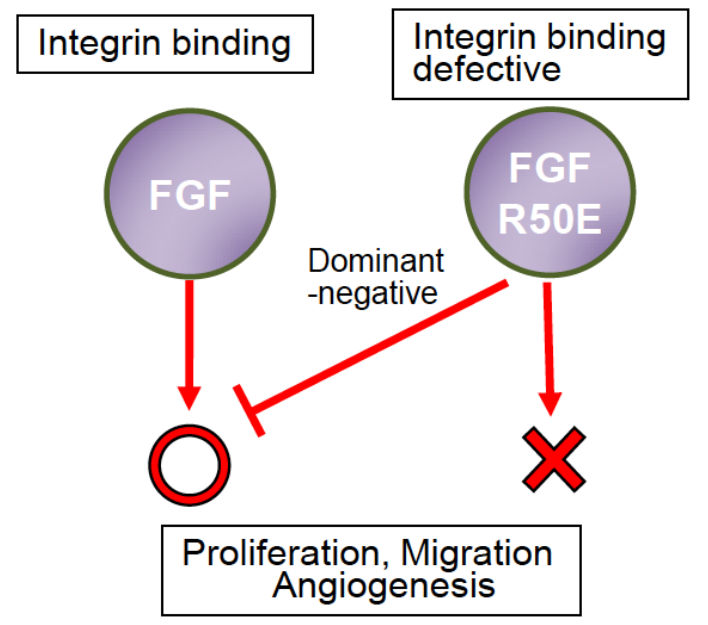

\section{Potential Advantage of R50E over Antibodies and Kinase Inhibitors}

The potential advantage of the FGF1 mutant is that: (1) R50E is highly specific to FGFR1 compared to tyrosine kinase inhibitors, which are selective rather than specific; (2) R50E has high affinity to FGFR1 ( $\mathrm{Kd} 10^{-12} \mathrm{M}$ ); (3) R50E binds to all FGFR isoforms and, thus, is expected to suppress signaling by other members of the FGF family (indeed, R50E (an FGF1 mutant) suppressed angiogenesis induced by FGF2 [89]); (4) R50E (17 Kd) is much smaller than $\operatorname{IgG}(180 \mathrm{Kd})$ and is expected to have better penetrance (access to cancer tissues) than antibodies; and (5) currently used target therapeutics (antibodies and kinase inhibitors) almost always induce resistance after a while. This is partly due to point mutations in antibody epitopes or inhibitor-binding sites. Cancer cells obviously benefit from mutations that block the binding of antagonists. R50E may not induce such 
mutations in FGFR because R50E and wild-type (WT) FGF1 bind to FGFR exactly the same way, and blocking binding of WT FGF1 (and other members of the FGF family) to FGFR would not benefit cancer cells; (6) FGF may bind to multiple integrins, and therefore, antagonists to multiple integrins would be required for effectively suppressing FGF-integrin crosstalk. In contrast, the R50E mutation is expected to effectively suppress integrin binding to FGF1 regardless of the integrin species involved.

\section{Can Mutant Human Protein Be Used As a Therapeutic Agent?}

There is a precedent that a mutant of human protein be used for human diseases. A mutant of human growth hormone (hGH) has been used as an antagonist of the $\mathrm{GH}$ receptor in the treatment of acromegaly (Pegvisomant) [90]. The Gly-120 of hGH was mutated to Arg (G120R), and this mutant was further modified by poly(ethylene glycol) (PEG)-5000 to elongate half-life. Pegvisomant prevents functional dimerization of the hGH receptor by sterically inhibiting conformational changes within the GH receptor dimers [90]. Pegvisomant is generally well-tolerated, with a safety profile similar to that reported in clinical trials, and can effectively reduce IGF1 in patients with acromegaly refractory to conventional therapy [91].

\section{Targeting and Delivery of R50E to Cancer}

It would be challenging to use R50E as a potential therapeutic, because exogenous growth factors are usually quickly cleared from circulation. It is expected that free FGF1 or R50E has a short half-life in vivo, and it is critical to stabilize and target $\mathrm{R} 50 \mathrm{E}$ in vivo to the tumor tissues in order to effectively suppress FGF signaling. Most nanoparticles are expected to accumulate in tumors, due to the enhanced permeation and retention (EPR) effects, a tumor characteristic as a means to target anticancer agents to tumors [92]. This one possibility is to deliver R50E as part of a nanoparticle. The good news is that WT FGF1 has already been tested in vivo and in clinical trials in angiogenic therapy. WT FGF1 has been delivered using two established methods: (1) sustained release [93,94]—WT FGF1 is encapsulated in heparin-alginate microparticles - and (2) plasmid-mediated gene transfer [95]. Intramuscular administration of FGF1 plasmid induces localized expression and transient systemic distribution of the plasmid. The WT FGF1 expression plasmid can be repeatedly and safely injected at multiple sites to achieve a broad distribution of FGF1 transgene protein [96]. We expect that R50E can be delivered using these methods. We will probably be able to exploit the delivery methods for WT FGF1 for angiogenic therapy to deliver R50E for anti-angiogenic therapy.

\section{Conclusions}

Although it has been well-established that integrins are involved in FGF signaling in biological and pathological conditions $[6,97,98]$, the specifics in the crosstalk have not been established. We obtained evidence that FGF1 directly binds to integrin $\alpha v \beta 3$, and this interaction is critically involved in FGF signaling. We propose a model in which FGF binding to FGFR induces integrin $\alpha v \beta 3$ to the complex, resulting in the ternary complex formation. The integrin-binding defective R50E is defective in signaling and ternary complex formation, while it still binds to FGFR and heparin. We demonstrated that R50E is dominant-negative, as predicted by the model. R50E suppresses signaling induced by WT 
FGF1 and FGF2 and suppresses tumorigenesis and angiogenesis. R50E has potential as an anti-cancer and anti-angiogenesis therapeutic agent ("FGF1-decoy"). R50E has several advantages over currently available targeting therapeutics: (1) R50E has high affinity and high specificity to FGFR (in contrast to kinase inhibitors that are selective, but not specific); (2) R50E binds to all FGFR isoforms and suppresses signaling by other members of the FGF family; (3) R50E is much smaller than IgG and is expected to have penetrance better than antibodies; and (4) the R50E mutation is expected to suppress integrin binding to FGF1, regardless of the integrin species involved.

\section{Acknowledgments}

We thank the members of the laboratories for their contributions to some of the findings described in this review. This work was supported by a Grant-in-Aid for Scientific Research (Grant No. 23590446) from the Japan Society for the Promotion of Science (to SM) and by NIH CA13015 and DOD W81XWH-10-1-0312 (to YT).

\section{Conflict of Interest}

The authors declare no conflict of interest.

\section{References}

1. Schwartz, M.A.; Ginsberg, M.H. Networks and crosstalk: Integrin signalling spreads. Nat. Cell Biol. 2002, 4, E65-E68.

2. Itoh, N.; Ornitz, D.M. Evolution of the FGF and FGFR gene families. Trends Genet. 2004, 20, 563-569.

3. Beenken, A.; Mohammadi, M. The FGF family: Biology, pathophysiology and therapy. Nat. Rev. Drug Discov. 2009, 8, 235-253.

4. Guillemot, F.; Zimmer, C. From cradle to grave: The multiple roles of fibroblast growth factors in neural development. Neuron 2011, 71, 574-588.

5. Polanska, U.M.; Fernig, D.G.; Kinnunen, T. Extracellular interactome of the FGF receptor-ligand system: Complexities and the relative simplicity of the worm. Dev. Dyn. 2009, 238, 277-293.

6. Murakami, M.; Elfenbein, A.; Simons, M. Non-canonical fibroblast growth factor signalling in angiogenesis. Cardiovasc. Res. 2008, 78, 223-231.

7. Takada, Y.; Ye, X.; Simon, S. The integrins. Genome Biol. 2007, doi:10.1186/gb-2007-8-5-215.

8. Legate, K.R.; Wickstrom, S.A.; Fassler, R. Genetic and cell biological analysis of integrin outside-in signaling. Genes Dev. 2009, 23, 397-418.

9. Ivaska, J.; Heino, J. Interplay between cell adhesion and growth factor receptors: From the plasma membrane to the endosomes. Cell Tissue Res. 2010, 339, 111-120.

10. Mori, S.; Wu, C.Y.; Yamaji, S.; Saegusa, J.; Shi, B.; Ma, Z.; Kuwabara, Y.; Lam, K.S.; Isseroff, R.R.; Takada, Y.K.; et al. Direct binding of integrin $\alpha \mathrm{v} \beta 3$ to FGF1 plays a role in FGF1 signaling. J. Biol. Chem. 2008, 283, 18066-18075.

11. Lanner, F.; Rossant, J. The role of FGF/ERK signaling in pluripotent cells. Development 2010, 137, 3351-3360. 
12. Jackson, A.; Tarantini, F.; Gamble, S.; Friedman, S.; Maciag, T. The release of fibroblast growth factor-1 from NIH 3T3 cells in response to temperature involves the function of cysteine residues. J. Biol. Chem. 1995, 270, 33-36.

13. Shi, J.; Friedman, S.; Maciag, T. A carboxyl-terminal domain in fibroblast growth factor (FGF)-2 inhibits FGF-1 release in response to heat shock in vitro. J. Biol. Chem. 1997, 272, 1142-1147.

14. Mouta Carreira, C.; Landriscina, M.; Bellum, S.; Prudovsky, I.; Maciag, T. The comparative release of FGF1 by hypoxia and temperature stress. Growth Factors 2001, 18, 277-285.

15. Schafer, T.; Zentgraf, H.; Zehe, C.; Brugger, B.; Bernhagen, J.; Nickel, W. Unconventional secretion of fibroblast growth factor 2 is mediated by direct translocation across the plasma membrane of mammalian cells. J. Biol. Chem. 2004, 279, 6244-6251.

16. Mohan, S.K.; Rani, S.G.; Yu, C. The heterohexameric complex structure, a component in the non-classical pathway for fibroblast growth factor 1 (FGF1) secretion. J. Biol. Chem. 2010, 285, $15464-15475$.

17. Goldfarb, M. Fibroblast growth factor homologous factors: Evolution, structure, and function. Cytokine Growth Factor Rev. 2005, 16, 215-220.

18. Schoorlemmer, J.; Goldfarb, M. Fibroblast growth factor homologous factors are intracellular signaling proteins. Curr. Biol. 2001, 11, 793-797.

19. Liu, C.; Dib-Hajj, S.D.; Waxman, S.G. Fibroblast growth factor homologous factor $1 \beta$ binds to the $\mathrm{c}$ terminus of the tetrodotoxin-resistant sodium channel rnav1.9a (nan). J. Biol. Chem. 2001, 276, 18925-18933.

20. Tomlinson, E.; Fu, L.; John, L.; Hultgren, B.; Huang, X.; Renz, M.; Stephan, J.P.; Tsai, S.P.; Powell-Braxton, L.; French, D.; et al. Transgenic mice expressing human fibroblast growth factor-19 display increased metabolic rate and decreased adiposity. Endocrinology 2002, 143, 1741-1747.

21. Kharitonenkov, A.; Shiyanova, T.L.; Koester, A.; Ford, A.M.; Micanovic, R.; Galbreath, E.J.; Sandusky, G.E.; Hammond, L.J.; Moyers, J.S.; Owens, R.A.; et al. FGF-21 as a novel metabolic regulator. J. Clin. Invest. 2005, 115, 1627-1635.

22. Shimada, T.; Kakitani, M.; Yamazaki, Y.; Hasegawa, H.; Takeuchi, Y.; Fujita, T.; Fukumoto, S.; Tomizuka, K.; Yamashita, T. Targeted ablation of FGF23 demonstrates an essential physiological role of FGF23 in phosphate and vitamin d metabolism. J. Clin. Invest. 2004, 113, 561-568.

23. Gospodarowicz, D. Purification of a fibroblast growth factor from bovine pituitary. J. Biol. Chem. 1975, 250, 2515-2520.

24. Itoh, N.; Ornitz, D.M. Fibroblast growth factors: From molecular evolution to roles in development, metabolism and disease. J. Biochem. 2011, 149, 121-130.

25. Miller, D.L.; Ortega, S.; Bashayan, O.; Basch, R.; Basilico, C. Compensation by fibroblast growth factor 1 (FGF1) does not account for the mild phenotypic defects observed in FGF2 null mice. Mol. Cell Biol. 2000, 20, 2260-2268.

26. Zhou, M.; Sutliff, R.L.; Paul, R.J.; Lorenz, J.N.; Hoying, J.B.; Haudenschild, C.C.; Yin, M.; Coffin, J.D.; Kong, L.; Kranias, E.G.; et al. Fibroblast growth factor 2 control of vascular tone. Nat. Med. 1998, 4, 201-207.

27. Dono, R.; Texido, G.; Dussel, R.; Ehmke, H.; Zeller, R. Impaired cerebral cortex development and blood pressure regulation in FGF-2-deficient mice. EMBO J. 1998, 17, 4213-4225. 
28. Powers, C.J.; McLeskey, S.W.; Wellstein, A. Fibroblast growth factors, their receptors and signaling. Endocr. Relat. Cancer 2000, 7, 165-197.

29. Groth, C.; Lardelli, M. The structure and function of vertebrate fibroblast growth factor receptor 1. Int. J. Dev. Biol. 2002, 46, 393-400.

30. Mohammadi, M.; Olsen, S.K.; Ibrahimi, O.A. Structural basis for fibroblast growth factor receptor activation. Cytokine Growth Factor Rev. 2005, 16, 107-137.

31. Zhang, X.; Ibrahimi, O.A.; Olsen, S.K.; Umemori, H.; Mohammadi, M.; Ornitz, D.M. Receptor specificity of the fibroblast growth factor family. The complete mammalian FGF family. J. Biol. Chem. 2006, 281, 15694-15700.

32. Turner, N.; Grose, R. Fibroblast growth factor signalling: From development to cancer. Nat. Rev. Cancer 2010, 10, 116-129.

33. Wesche, J.; Haglund, K.; Haugsten, E.M. Fibroblast growth factors and their receptors in cancer. Biochem. J. 2011, 437, 199-213.

34. Dorkin, T.J.; Robinson, M.C.; Marsh, C.; Bjartell, A.; Neal, D.E.; Leung, H.Y. FGF8 over-expression in prostate cancer is associated with decreased patient survival and persists in androgen independent disease. Oncogene 1999, 18, 2755-2761.

35. Feng, S.; Dakhova, O.; Creighton, C.J.; Ittmann, M. Endocrine fibroblast growth factor FGF19 promotes prostate cancer progression. Cancer Res. 2013, 73, 2551-2562.

36. Okunieff, P.; Fenton, B.M.; Zhang, L.; Kern, F.G.; Wu, T.; Greg, J.R.; Ding, I. Fibroblast growth factors (FGFs) increase breast tumor growth rate, metastases, blood flow, and oxygenation without significant change in vascular density. Adv. Exp. Med. Biol. 2003, 530, 593-601.

37. Gruel, N.; Lucchesi, C.; Raynal, V.; Rodrigues, M.J.; Pierron, G.; Goudefroye, R.; Cottu, P.; Reyal, F.; Sastre-Garau, X.; Fourquet, A.; et al. Lobular invasive carcinoma of the breast is a molecular entity distinct from luminal invasive ductal carcinoma. Eur. J. Cancer 2010, 46, 2399-2407.

38. Naidu, R.; Wahab, N.A.; Yadav, M.; Kutty, M.K.; Nair, S. Detection of amplified int-2/FGF-3 gene in primary breast carcinomas using differential polymerase chain reaction. Int. J. Mol. Med. 2001, 8, 193-198.

39. Birrer, M.J.; Johnson, M.E.; Hao, K.; Wong, K.K.; Park, D.C.; Bell, A.; Welch, W.R.; Berkowitz, R.S.; Mok, S.C. Whole genome oligonucleotide-based array comparative genomic hybridization analysis identified fibroblast growth factor 1 as a prognostic marker for advanced-stage serous ovarian adenocarcinomas. J. Clin. Oncol. 2007, 25, 2281-2287.

40. Giri, D.; Ropiquet, F.; Ittmann, M. Alterations in expression of basic fibroblast growth factor (FGF) 2 and its receptor FGFR-1 in human prostate cancer. Clin. Cancer Res. 1999, 5, 1063-1071.

41. Arora, N.; Scognamiglio, T.; Lubitz, C.C.; Moo, T.A.; Kato, M.A.; Zhu, B.; Zarnegar, R.; Chen, Y.T.; Fahey, T.J., 3rd. Identification of borderline thyroid tumors by gene expression array analysis. Cancer 2009, 115, 5421-5431.

42. Zhang, Y.; Wang, H.; Toratani, S.; Sato, J.D.; Kan, M.; McKeehan, W.L.; Okamoto, T. Growth inhibition by keratinocyte growth factor receptor of human salivary adenocarcinoma cells through induction of differentiation and apoptosis. Proc. Natl. Acad. Sci. USA 2001, 98, 11336-11340. 
43. Amann, T.; Bataille, F.; Spruss, T.; Dettmer, K.; Wild, P.; Liedtke, C.; Muhlbauer, M.; Kiefer, P.; Oefner, P.J.; Trautwein, C.; et al. Reduced expression of fibroblast growth factor receptor 2 iiib in hepatocellular carcinoma induces a more aggressive growth. Am. J. Pathol. 2010, 176, 1433-1442.

44. Nakamura, N.; Iijima, T.; Mase, K.; Furuya, S.; Kano, J.; Morishita, Y.; Noguchi, M. Phenotypic differences of proliferating fibroblasts in the stroma of lung adenocarcinoma and normal bronchus tissue. Cancer Sci. 2004, 95, 226-232.

45. Presta, M.; Dell'Era, P.; Mitola, S.; Moroni, E.; Ronca, R.; Rusnati, M. Fibroblast growth factor/fibroblast growth factor receptor system in angiogenesis. Cytokine Growth Factor Rev. 2005, 16, 159-178.

46. Hynes, R.O. Integrins: Bidirectional, allosteric signaling machines. Cell 2002, 110, 673-687.

47. Mahabeleshwar, G.H.; Feng, W.; Reddy, K.; Plow, E.F.; Byzova, T.V. Mechanisms of integrin-vascular endothelial growth factor receptor cross-activation in angiogenesis. Circ. Res. 2007, 101, 570-580.

48. Borges, E.; Jan, Y.; Ruoslahti, E. Platelet-derived growth factor receptor $\beta$ and vascular endothelial growth factor receptor 2 bind to the $\beta 3$ integrin through its extracellular domain. J. Biol. Chem. 2000, 275, 39867-39873.

49. Cybulsky, A.V.; McTavish, A.J.; Cyr, M.D. Extracellular matrix modulates epidermal growth factor receptor activation in rat glomerular epithelial cells. J. Clin. Invest. 1994, 94, 68-78.

50. Soldi, R.; Mitola, S.; Strasly, M.; Defilippi, P.; Tarone, G.; Bussolino, F. Role of $\alpha v \beta 3$ integrin in the activation of vascular endothelial growth factor receptor-2. EMBO J. 1999, 18, 882-892.

51. Clemmons, D.R.; Horvitz, G.; Engleman, W.; Nichols, T.; Moralez, A.; Nickols, G.A. Synthetic $\alpha v \beta 3$ antagonists inhibit insulin-like growth factor-i-stimulated smooth muscle cell migration and replication. Endocrinology 1999, 140, 4616-4621.

52. Jones, P.L.; Crack, J.; Rabinovitch, M. Regulation of tenascin-c, a vascular smooth muscle cell survival factor that interacts with the $\alpha \mathrm{v} \beta 3$ integrin to promote epidermal growth factor receptor phosphorylation and growth. J. Cell Biol. 1997, 139, 279-293.

53. Brooks, P.C.; Clark, R.A.; Cheresh, D.A. Requirement of vascular integrin $\alpha v \beta 3$ for angiogenesis. Science 1994, 264, 569-571.

54. Friedlander, M.; Brooks, P.C.; Shaffer, R.W.; Kincaid, C.M.; Varner, J.A.; Cheresh, D.A. Definition of two angiogenic pathways by distinct $\alpha$ v integrins. Science 1995, 270, 1500-1502.

55. Eliceiri, B.P.; Klemke, R.; Stromblad, S.; Cheresh, D.A. Integrin $\alpha v \beta 3$ requirement for sustained mitogen-activated protein kinase activity during angiogenesis. J. Cell Biol. 1998, 140, 1255-1263.

56. Kim, S.; Bell, K.; Mousa, S.A.; Varner, J.A. Regulation of angiogenesis in vivo by ligation of integrin $\alpha 5 \beta 1$ with the central cell-binding domain of fibronectin. Am. J. Pathol. 2000, 156, $1345-1362$.

57. Zou, L.; Cao, S.; Kang, N.; Huebert, R.C.; Shah, V.H. Fibronectin induces endothelial cell migration through $\beta 1$ integrin and src-dependent phosphorylation of fibroblast growth factor receptor-1 at tyrosines 653/654 and 766. J. Biol. Chem. 2012, 287, 7190-7202.

58. Schneller, M.; Vuori, K.; Ruoslahti, E. $\alpha v \beta 3$ integrin associates with activated insulin and PDGF $\beta$ receptors and potentiates the biological activity of PDGF. EMBO J. 1997, 16, 5600-5607.

59. Mahabeleshwar, G.H.; Chen, J.; Feng, W.; Somanath, P.R.; Razorenova, O.V.; Byzova, T.V. Integrin affinity modulation in angiogenesis. Cell Cycle 2008, 7, 335-347. 
60. Saegusa, J.; Yamaji, S.; Ieguchi, K.; Wu, C.Y.; Lam, K.S.; Liu, F.T.; Takada, Y.K.; Takada, Y. The direct binding of insulin-like growth factor-1 (IGF-1) to integrin $\alpha v \beta 3$ is involved in IGF-1 signaling. J. Biol. Chem. 2009, 284, 24106-24114.

61. Fujita, M.; Ieguchi, K.; Davari, P.; Yamaji, S.; Taniguchi, Y.; Sekiguchi, K.; Takada, Y.K.; Takada, Y. Cross-talk between integrin $\alpha 6 \beta 4$ and insulin-like growth factor-1 receptor (igflr) through direct $\alpha 6 \beta 4$ binding to IGF1 and subsequent $\alpha 6 \beta 4-I G F 1-I G F 1 R$ ternary complex formation in anchorage-independent conditions. J. Biol. Chem. 2012, 287, 12491-12500.

62. Ieguchi, K.; Fujita, M.; Ma, Z.; Davari, P.; Taniguchi, Y.; Sekiguchi, K.; Wang, B.; Takada, Y.K.; Takada, Y. Direct binding of the EGF-like domain of neuregulin-1 to integrins ( $\alpha \mathrm{v} \beta 3$ and $\alpha 6 \beta 4)$ is involved in neuregulin-1/ErbB signaling. J. Biol. Chem. 2010, 285, 31388-31398.

63. Vlahakis, N.E.; Young, B.A.; Atakilit, A.; Sheppard, D. The lymphangiogenic vascular endothelial growth factors VEGF-C and -D are ligands for the integrin $\alpha 9 \beta 1$. J. Biol. Chem. 2005, $280,4544-4552$.

64. Hutchings, H.; Ortega, N.; Plouet, J. Extracellular matrix-bound vascular endothelial growth factor promotes endothelial cell adhesion, migration, and survival through integrin ligation. FASEB J. 2003, 17, 1520-1522.

65. Vlahakis, N.E.; Young, B.A.; Atakilit, A.; Hawkridge, A.E.; Issaka, R.B.; Boudreau, N.; Sheppard, D. Integrin $\alpha 9 \beta 1$ directly binds to vascular endothelial growth factor (VEGF)-A and contributes to VEGF-A-induced angiogenesis. J. Biol. Chem. 2007, 282, 15187-15196.

66. Munger, J.S.; Huang, X.; Kawakatsu, H.; Griffiths, M.J.; Dalton, S.L.; Wu, J.; Pittet, J.F.; Kaminski, N.; Garat, C.; Matthay, M.A.; et al. The integrin $\alpha v \beta 6$ binds and activates latent TGF $\beta$ 1: A mechanism for regulating pulmonary inflammation and fibrosis. Cell 1999, 96, 319-328.

67. Cambier, S.; Gline, S.; Mu, D.; Collins, R.; Araya, J.; Dolganov, G.; Einheber, S.; Boudreau, N.; Nishimura, S.L. Integrin $\alpha v \beta 8$-mediated activation of transforming growth factor- $\beta$ by perivascular astrocytes: An angiogenic control switch. Am. J. Pathol. 2005, 166, 1883-1894.

68. Carlson, T.R.; Feng, Y.; Maisonpierre, P.C.; Mrksich, M.; Morla, A.O. Direct cell adhesion to the angiopoietins mediated by integrins. J. Biol. Chem. 2001, 276, 26516-26525.

69. Bezuidenhout, L.; Zilla, P.; Davies, N. Association of ang-2 with integrin $\beta 2$ controls ang-2/PDGF-BB-dependent upregulation of human peripheral blood monocyte fibrinolysis. Inflammation 2009, 32, 393-401.

70. Andre, P.; Prasad, K.S.; Denis, C.V.; He, M.; Papalia, J.M.; Hynes, R.O.; Phillips, D.R.; Wagner, D.D. CD40L stabilizes arterial thrombi by a $\beta 3$ integrin--dependent mechanism. Nat. Med. 2002, 8, 247-252.

71. Leveille, C.; Bouillon, M.; Guo, W.; Bolduc, J.; Sharif-Askari, E.; El-Fakhry, Y.; Reyes-Moreno, C.; Lapointe, R.; Merhi, Y.; Wilkins, J.A.; et al. CD40 ligand binds to $\alpha 5 \beta 1$ integrin and triggers cell signaling. J. Biol. Chem. 2007, 282, 5143-5151.

72. Zirlik, A.; Maier, C.; Gerdes, N.; MacFarlane, L.; Soosairajah, J.; Bavendiek, U.; Ahrens, I.; Ernst, S.; Bassler, N.; Missiou, A.; et al. CD40 ligand mediates inflammation independently of CD40 by interaction with mac-1. Circulation 2007, 115, 1571-1580.

73. Rusnati, M.; Tanghetti, E.; Dell'Era, P.; Gualandris, A.; Presta, M. $\alpha v \beta 3$ integrin mediates the cell-adhesive capacity and biological activity of basic fibroblast growth factor (FGF-2) in cultured endothelial cells. Mol. Biol. Cell 1997, 8, 2449-2461. 
74. Fujita, M.; Takada, Y.K.; Takada, Y. Integrins $\alpha v \beta 3$ and $\alpha 4 \beta 1$ act as coreceptors for fractalkine, and the integrin-binding defective mutant of fractalkine is an antagonist of CX3CR1. J. Immunol. 2012, 189, 5809-5819.

75. Nakamura, K.; Iwamoto, R.; Mekada, E. Membrane-anchored heparin-binding EGF-like growth factor (HB-EGF) and diphtheria toxin receptor-associated protein (drap27)/CD9 form a complex with integrin $\alpha 3 \beta 1$ at cell-cell contact sites. J. Cell Biol. 1995, 129, 1691-1705.

76. Staniszewska, I.; Sariyer, I.K.; Lecht, S.; Brown, M.C.; Walsh, E.M.; Tuszynski, G.P.; Safak, M.; Lazarovici, P.; Marcinkiewicz, C. Integrin $\alpha 9 \beta 1$ is a receptor for nerve growth factor and other neurotrophins. J. Cell Sci. 2008, 121, 504-513.

77. Suzuki, K.; Okuno, T.; Yamamoto, M.; Pasterkamp, R.J.; Takegahara, N.; Takamatsu, H.; Kitao, T.; Takagi, J.; Rennert, P.D.; Kolodkin, A.L.; et al. Semaphorin 7a initiates t-cell-mediated inflammatory responses through $\alpha 1 \beta 1$ integrin. Nature 2007, 446, 680-684.

78. Tanghetti, E.; Ria, R.; Dell'Era, P.; Urbinati, C.; Rusnati, M.; Ennas, M.G.; Presta, M. Biological activity of substrate-bound basic fibroblast growth factor (FGF2): Recruitment of FGF receptor-1 in endothelial cell adhesion contacts. Oncogene 2002, 21, 3889-3897.

79. Sahni, A.; Francis, C.W. Stimulation of endothelial cell proliferation by FGF-2 in the presence of fibrinogen requires $\alpha v \beta 3$. Blood 2004, 104, 3635-3641.

80. Sahni, A.; Khorana, A.A.; Baggs, R.B.; Peng, H.; Francis, C.W. FGF-2 binding to fibrin(ogen) is required for augmented angiogenesis. Blood 2006, 107, 126-131.

81. Sahni, A.; Altland, O.D.; Francis, C.W. FGF-2 but not FGF-1 binds fibrin and supports prolonged endothelial cell growth. J. Thromb. Haemost. 2003, 1, 1304-1310.

82. Yamaji, S.; Saegusa, J.; Ieguchi, K.; Fujita, M.; Mori, S.; Takada, Y.K.; Takada, Y. A novel fibroblast growth factor-1 (FGF1) mutant that acts as an FGF antagonist. PLoS One 2010, 5, e10273.

83. Takagi, J.; Petre, B.M.; Walz, T.; Springer, T.A. Global conformational rearrangements in integrin extracellular domains in outside-in and inside-out signaling. Cell 2002, 110, 599-611.

84. Xiong, J.P.; Stehle, T.; Zhang, R.; Joachimiak, A.; Frech, M.; Goodman, S.L.; Arnaout, M.A. Crystal structure of the extracellular segment of integrin $\alpha v \beta 3$ in complex with an Arg-Gly-Asp ligand. Science 2002, 296, 151-155.

85. Beglova, N.; Blacklow, S.C.; Takagi, J.; Springer, T.A. Cysteine-rich module structure reveals a fulcrum for integrin rearrangement upon activation. Nat. Struct. Biol. 2002, 9, 282-287.

86. Adair, B.D.; Xiong, J.P.; Maddock, C.; Goodman, S.L.; Arnaout, M.A.; Yeager, M. Three-dimensional em structure of the ectodomain of integrin $\alpha v \beta 3$ in a complex with fibronectin. J. Cell Biol. 2005, 168, 1109-1118.

87. Sharrocks, A.D. Cell cycle: Sustained ERK signalling represses the inhibitors. Curr. Biol. 2006, 16, R540-R542.

88. Schlessinger, J.; Plotnikov, A.N.; Ibrahimi, O.A.; Eliseenkova, A.V.; Yeh, B.K.; Yayon, A.; Linhardt, R.J.; Mohammadi, M. Crystal structure of a ternary FGF-FGFR-heparin complex reveals a dual role for heparin in FGFR binding and dimerization. Mol. Cell 2000, 6, 743-750.

89. Mori, S.; Tran, V.; Nishikawa, K.; Kaneda, T.; Hamada, Y.; Kawaguchi, N.; Fujita, M.; Takada, Y.K.; Matsuura, N.; Zhao, M.; et al. A dominant-negative FGF1 mutant (the R50E mutant) suppresses tumorigenesis and angiogenesis. PLoS One 2013, 8, e57927. 
90. Kopchick, J.J.; Parkinson, C.; Stevens, E.C.; Trainer, P.J. Growth hormone receptor antagonists: Discovery, development, and use in patients with acromegaly. Endocr. Rev. 2002, 23, 623-646.

91. Schreiber, I.; Buchfelder, M.; Droste, M.; Forssmann, K.; Mann, K.; Saller, B.; Strasburger, C.J. Treatment of acromegaly with the gh receptor antagonist pegvisomant in clinical practice: Safety and efficacy evaluation from the german pegvisomant observational study. Eur. J. Endocrinol. 2007, 156, 75-82.

92. Wang, M.; Thanou, M. Targeting nanoparticles to cancer. Pharmacol. Res. 2010, 62, 90-99.

93. Moya, M.L.; Morley, M.; Khanna, O.; Opara, E.C.; Brey, E.M. Stability of alginate microbead properties in vitro. J. Mater. Sci. Mater. Med. 2012, 23, 903-912.

94. Khanna, O.; Moya, M.L.; Opara, E.C.; Brey, E.M. Synthesis of multilayered alginate microcapsules for the sustained release of fibroblast growth factor-1. J. Biomed. Mater. Res. A 2010, 95, 632-640.

95. Witzenbichler, B.; Mahfoudi, A.; Soubrier, F.; Le Roux, A.; Branellec, D.; Schultheiss, H.P.; Isner, J.M. Intramuscular gene transfer of fibroblast growth factor-1 using improved pcor plasmid design stimulates collateral formation in a rabbit ischemic hindlimb model. J. Mol. Med. (Berl) 2006, 84, 491-502.

96. Baumgartner, I.; Chronos, N.; Comerota, A.; Henry, T.; Pasquet, J.P.; Finiels, F.; Caron, A.; Dedieu, J.F.; Pilsudski, R.; Delaere, P. Local gene transfer and expression following intramuscular administration of FGF-1 plasmid DNA in patients with critical limb ischemia. Mol. Ther. 2009, 17, 914-921.

97. Eliceiri, B.P. Integrin and growth factor receptor crosstalk. Circ. Res. 2001, 89, 1104-1110.

98. Somanath, P.R.; Ciocea, A.; Byzova, T.V. Integrin and growth factor receptor alliance in angiogenesis. Cell Biochem. Biophys. 2009, 53, 53-64.

(C) 2013 by the authors; licensee MDPI, Basel, Switzerland. This article is an open access article distributed under the terms and conditions of the Creative Commons Attribution license (http://creativecommons.org/licenses/by/3.0/). 